\title{
National indicators of climate changes, impacts, and vulnerability
}

\author{
Melissa A. Kenney ${ }^{1}$ (D) Anthony C. Janetos ${ }^{2}$
}

Received: 28 October 2020 / Accepted: 5 November 2020/Published online: 14 November 2020

(C) The Author(s) 2020

\section{Introduction}

Climate assessment efforts in the USA are a legally required and important process to share the state of knowledge about status and projected trends of climate changes and impacts and are used to support risk management decisions and policies (Jacobs et al. 2016). One of the major gaps in our ability to effectively conduct assessments as a scientific community has been the challenge of systematically tracking climate impacts relative to a baseline, especially their magnitude and distribution for socio-environmental systems and sectors, and to assess the effectiveness of our climate actions (Janetos and Kenney 2015). Indicators have been proposed as a means to address this gap.

Kenney et al. (2016) define indicators as

"reference tools that can be used to regularly update status, rates of change, or trends of a phenomenon using measured data, modeled data, or an index to assess or advance scientific understanding, to communicate, to inform decision-making, or to denote progress in achieving management objectives. Indicators differ from data visualization tools in that they are systematically updated and comparative to a baseline of change."

Indicators have been highlighted as a foundational decision support product to consistently report changes relative to a baseline for phenomena of national importance and presenting them in a manner that is relevant to a broad range of decision-makers. Specifically, an important feature of the 3rd US National Climate Assessment (NCA), and the sustained assessment process that was initiated, was to develop climate-relevant information and products, such as indicators, for use by a wide variety of stakeholders in

This article is part of a Special Issue on "National Indicators of Climate Changes, Impacts, and Vulnerability" edited by Anthony C. Janetos and Melissa A. Kenney

Melissa A. Kenney

makenney@umn.edu

1 Institute on the Environment, University of Minnesota, 1954 Buford Ave., Suite 325, Saint Paul, MN 55108, USA

2 Frederick S. Pardee Center for the Study of the Longer-Range Future, Boston University, 67 Bay State Road, 685 Commonwealth Avenue, Boston, MA 02215, USA 
public and private sectors and in the scientific community (Buizer et al. 2013, 2016; Jacobs et al. 2016). The participatory process and use-based framing of the NCA, including the establishment of indicators, was further expanded as a recommendation by the sustained NCA Federal Advisory Committee, which was disbanded in 2017 (Moss et al. 2019).

To meet the need for a system of NCA indicators, we (A.C. Janetos and M.A. Kenney) led an effort to develop recommendations to establish an indicator system for the NCA. The process, which is summarized in Kenney et al. (2016), was initiated through a series of workshops (U.S. Global Change Research Program 2010, 2011a, b). Subsequently, first, a steering committee (called the Indicator Working Group) was established to develop criteria and an overall vision for an indicators system, and second, sector- or system-focused teams were charged with developing conceptual models, indicators recommendations, and research priorities (Janetos et al. 2012; Kenney et al. 2014). Overall the effort included over 200 natural and social scientists and practitioners from academia, federal agencies, non-governmental organizations (NGOs), and the private sector.

The system proposed (Janetos et al. 2012; Kenney et al. 2014) was designed to be inclusive of the most important climate changes, impacts, vulnerabilities, and preparedness, including those aspects that occur in a multi-stressor context. These components serve as categories within which to organize an end-to-end system of indicators and include:

- Greenhouse gas emissions and sinks

- Atmospheric composition

- Physical climate variability and change

- Sectors and resources of concern

- Adaptation and mitigation

The National Climate Assessment Development and Advisory Committee (NCADAC), the Federal Advisory Committee for the 3rd NCA, and its subsidiary Indicator Working Group suggested a system that would have both a pilot phase and a more complete implementation phase. These recommendations led to indicators that were developed as a proof-of-concept and initially launched by the US Global Change Research Program (USGCRP) in 2015 (https://www.globalchange.gov/indicators). Independent of the teams that constructed the recommendations, the indicators were continued, managed, and operationalized by USGCRP, for inclusion in the 4th NCA (U.S. Global Change Research Program 2018). A more complete implementation of the indicator system continues to be an aspiration of the authors of this special issue.

This special issue reflects a decade of work to develop frameworks for national indicators of climate changes, impacts, and vulnerability, through the use of conceptual models, to scientifically justify the selection of indicators and research priorities for both an overall system and the components of such a system. It additionally explores coupled human-natural climate indicators in different geographic locations and at different scales. And finally, the issue tackles the design of individual indicators to meet the goals of the indicator system and to communicate indicators effectively so that wide audiences understand them. 


\section{Contributions to this special issue}

The first paper in this special issue is A framework for national climate indicators (Kenney et al. 2018). The paper establishes the goals for an effort to support US climate assessments by emphasizing the goal of establishing consistent baselines to describe multi-stressor impacts, system resilience, and planning and policy progress. This paper presents the selection criteria, which include end-to-end from emissions to responses, conceptually justified, climate connection, nationally important, and useful. This end-to-end, hierarchical conceptual framework for a US climate indicator system includes the relationships between the atmosphere and climate; terrestrial, aquatic, and built environment systems and sectors; phenological changes; human health implications; and mitigation and adaptation responses (Kenney et al. 2018, Fig. 2). The individual indicators would focus on climate changes, impacts, vulnerabilities, and responses Kenney et al. (2018; Table 1 and Online Resources), provided within topical groupings of the types of indicators that would be expected under the different systems and/ or sectors.

Other papers in this special issue focus on building out the conceptual model further for their system or sector and providing indicator recommendations and priorities. Papers were not included on climate change indicators - either global impacts or US changes and variabilitybecause many are already established and regularly tracked, or on adaptation response indicators as they largely present a research opportunity.

In the first topical paper, Toward an integrated system of climate change and human health indicators: a conceptual framework (Liu et al. in preparation), the human health implications of climate change were explored to identify indicators. The authors propose a conceptual framework for an indicator system based on multi-stressor exposure-outcome pathways that connect climate, environment, health, population vulnerability, and adaptation factors. This conceptual model is applied using several climate-sensitive health outcomes as examples, notably allergies, West Nile virus infections, and vibriosis.

The terrestrial systems included three papers: agriculture, forest, and rangeland and pasture systems. In Indicators of climate change in agricultural systems (Hatfield et al. 2018), the authors develop a conceptual framework that links the climate system to crop and livestock productivity as well as the impacts of land on other grassland and forest systems. Importantly, the conceptual framework highlights the linkages between agricultural production and greenhouse gas emissions. The indicators highlighted-livestock heat stress, soil erosion and land use, soil organic matter changes, economic impacts of climate change on agricultural systems, and crop progress and productivity — best detected agricultural responses to climate changes.

Developing a set of indicators to identify, monitor, and track impacts and change in forests of the United States (Anderson et al. in preparation) details 11 key indicators of forest and climate change impacts which were developed from a conceptual model that focuses on the land use, ecosystem, and economic attributes of forest systems. The indicators recommended are forestland area and extent, forest biomass density, diversity/abundance of forest-associated floral and faunal species, forest growth/productivity, wildfire effects, forest insect and disease damage, water balance deficit, US wildland-urban interface, cost to mitigate wildfire risk, energy produced from forest-based biomass, and outdoor recreation. Unsurprisingly, there are nice synergies between the important indicators highlighted in this paper and a forest climate indicator effort developed for Canadian forest systems (Lorente et al. 2018).

A Climate change indicator framework for rangelands and pastures of the United States (Ojima et al. 2020) provides a socio-ecological conceptual framework for selecting indicators. 
The authors present several example indicators - evaporative demand, land cover extent, aboveground plant biomass, human demographics (population age distribution), cattle numbers, and economic value of cattle products relative to total agricultural value - which provide a starting point for establishing rangeland and pasture indicators to support understanding, planning, and evaluation.

In their paper Seasonality of biological and physical systems as indicators of climatic variation and change, Weltzin et al. (2020) include seasonal (i.e., temporally dynamic) representations of biological and physical indicators in terrestrial and freshwater aquatic ecosystems. They developed a rigorous process of indicator identification and selection to recommend indicators of the seasonality of surface climate conditions (e.g., first frost, last frost), seasonality of freeze/thaw or surficial runoff in freshwater systems, seasonality in ecosystem disturbances (e.g., fire), seasonality in vegetated land surfaces (e.g., timing of greenup, see also Jones et al. (2018)), and seasonality of organismal life-history stages (e.g., migration). These indicators have a strong causal relationship to climate change but also enable a more comprehensive understanding of spatiotemporal patterns, drivers, interactions, and feedback effects in temporally dynamic biological and physical systems.

The aquatic system included three papers: water cycle and management, freshwater ecosystems, and oceans and coasts systems. The first aquatic contribution, Indicators of climate change impacts on the water cycle and water management (Peters-Lidard et al. in preparation), describes 17 proposed indicators of hydrologic processes, water quality processes, and water quality and quantity impacts that could be readily implemented into a national system. The recommended indicators are average and heavy precipitation; standardized precipitation index; annual, 7-day low, and 3-day high streamflow volume; streamflow timing; snow cover; snow water equivalent; groundwater level; lake water temperature; stream water temperature; dissolved oxygen; salinity; Palmer Drought Severity Index; water withdrawals; and water use.

Indicators of the effects of climate change on freshwater ecosystems (Rose et al. in preparation) focuses on the climate impacts to lakes, streams, and wetlands. It develops a conceptual framework that identifies three indicator types: freshwater availability for aquatic and human uses, water and ecosystem quality, and biological structure and function to ecosystem services. These indicator recommendations are complementary to those in PetersLidard et al. (in preparation) and distinctively focused on freshwater systems.

In Ocean and coastal indicators: understanding and coping with climate change at the land-sea interface (Clay et al. in preparation), the authors present an ecosystem services conceptual framework for the ocean and coast indicators that include regulatory services, supporting services, and provisioning services, cultural services, and related livelihoods. Given this conceptual framework and selection criteria, the authors identified 21 biophysical and socioeconomic indicators and detail five of these indicators - aragonite saturation state, fish distribution, coral thermal stress, community climate vulnerability, and community social wellbeing - for more immediate inclusion in the indicator system.

The built environment includes two sectors: energy and infrastructure (Wilbanks et al. 2020). The energy sector indicator team was led by Tom Wilbanks (deceased). The initial recommendations focused on energy supply and use indicators and recommended including two indicators as a starting point for heating and cooling degree days and stress index of electricity generation (Kenney et al. 2014); since this work was released, there have been a number of advancements in indicators in the energy sector which could be drawn on for national efforts. 
In the paper, Toward indicators of the performance of U.S. infrastructures under climate change risks (Wilbanks et al. 2020), the authors consider indicators for over a dozen indicator types that fall into four different categories: (i) vulnerabilities and changes in the reliability of infrastructure services and the implications for costs, (ii) vulnerabilities and changes in the resilience of infrastructures to climate and other stresses, (iii) impacts due to the interdependencies of infrastructures, and (iv) adaptation actions and policies to reduce the vulnerability of infrastructure systems. A few illustrative examples are provided throughout the paper of these different indicator types.

In addition to the strong focus on multi-sector impact and vulnerability indicators represented in the terrestrial systems, aquatic systems, and built environment sectors, the system is designed to include adaptation and mitigation response indicators. Though adaptation indicators are highly desirable, Kenney and Gerst (in review) highlight that the majority of indicators focus on process (e.g., number of adaptation plans, type of adaptation actions) or effectiveness of a single project. Kenney and Gerst (in review) recommend the use of a resilience framework to establish regional adaptation effectiveness indicators. Such adaptation indicators are still largely a research opportunity; Janetos (2020) presents a generalized framework to focus research efforts toward indicators that inform adaptation decisions that minimize risk. The development of such indicators using either of these approaches is nascent, which is why a paper with recommendations is not included in this special issue; this is an area of research for a national system of indicators.

Mitigation indicators, in contrast, were proposed as part of the indicator system. In Observations of greenhouse gases as climate indicators, Bruhwiler et al. (in preparation) focus on atmospheric composition measurements which can be used to both understand current radiative forcing conditions and the effectiveness of emission reduction activities. The paper presents indicator recommendations in the categories of (i) atmospheric measurements of radiatively active atmospheric constituents as climate indicators (e.g., emissions inventories, carbon dioxide, methane, nitrous oxide, halocarbons), (ii) annual greenhouse gas index (the visualization effectiveness of which was tested in Gerst et al. (in preparation)), and (iii) other climate indicators. Both bottom-up inventory-based mitigation process measures and top-down modeling approaches were proposed as indicators to understand, predict, and assess mitigation effectiveness.

To explore coupled human-natural climate indicators in different locations, the special issue includes three papers: one paper explores the development of indicators for urban environments (Solecki and Rosenzweig 2020); a second describes the development of forest system indicators in Canada (Lorente et al. 2018); and the third recommends socio-environmental Arctic indicators (Stanitski et al. in preparation), a threshold location currently experiencing climate impacts. In Indicators and monitoring systems for urban climate resiliency (Solecki and Rosenzweig 2020), the authors review and assess the measurement of urban resilience efforts to identify, for the New York City Panel Climate Change, effective indicators and monitoring systems that support climate action. The authors use an example of urban heat island tracking to highlight the challenges and opportunities with indicators and monitoring, including the evaluation of specific adaptation actions and policies (e.g., cool roofs).

In Tracking forest changes: Canadian Forest Service indicators of climate change (Lorente et al. 2018), the authors describe a participatory process involving researchers and forest sector stakeholders to select and establish indicators of forest change. They present a web-based Forest Change Tracking System which includes 35 indicators of climate change, forest 
systems, and human dimensions to increase awareness and support adaptation decisionmaking and discuss opportunities to expand upon the initial system to meet user needs.

Indicators for a changing Arctic (Stanitski et al. in preparation) focuses on climate and socio-environmental indicators of the rapid changes occurring in the Arctic, to advance understanding and to support decision-making. The authors adopt the process used in this special issue to establish US multi-stressor impact and vulnerability indicators. They conducted a literature review to identify a set of priority biophysical and socioeconomic indicators that represented key Arctic processes and sectors in support of a range of Arctic and national-tointernational assessment efforts.

The last set of papers in the special issue explores indicator design: one paper presents different approaches to developing terrestrial primary productivity indicators (Jones et al. 2018), and a second paper tests the understandability of indicator visualizations for widereaching public audiences (Gerst et al. in preparation). In Terrestrial primary productivity indicators for inclusion in the National Climate Indicators System (Jones et al. 2018), the authors present a series of gross primary productivity (GPP) and net primary productivity (NPP) indicators that are consistent with criteria established for a national indicator system in Kenney et al. $(2016,2018)$ and which represent phenological changes that are relevant to the understanding and management of agriculture, forests, and rangelands and pasture terrestrial systems.

Last, in Improving the usability of climate indicator visualizations through diagnostic design principles (Gerst et al. in preparation), the authors test the effectiveness of diagnostic visualization guidelines on indicators included in the 3rd NCA and the proof-of-concept indicator system initially released. The approach identifies communication shortcomings and then specifies simplifications or annotations given best practices for climate indicators. Such modifications can then be control vs treatment tested to assess whether the modifications improve understanding and subjective reactions among the public. This study provides two key advancements to previous research by Gerst et al. (2020): (i) it explicitly examines the role of both simplifications and annotations in improving understandability, and (ii) it explores the impact of respondents' climate attitudes and beliefs, as well as political identities, on the understandability of climate visualizations and efforts to improve both understanding and subjective reactions. Results show that (i) simplifying design modifications helps improve the understandability of the graphics, but understanding is still dependent on general ability (i.e., education and numeracy) and (ii) ideology does not impede improved understanding associated with better design (i.e., motivated reasoning) and such modifications do not measurably counter ideologically based likability and mistrust in climate indicators. These findings point to diagnostic guidelines as a useful tool for creating more accessible, engaging climate indicators for the public.

\section{Conclusions}

The collection of papers that are part of this special issue are designed to provide recommendations on frameworks and indicators to build out a system of indicators in support of the NCA. Though there are indicators that can be built out immediately to develop a more robust system, there were a number of research opportunities that were highlighted within the special issue, namely, human dimensions indicators, adaptation indicators, leading indicators, and 
decision support evaluation. Additionally, an incremental process could achieve the aspirational vision of the indicators system over time.

Human dimension indicators were underdeveloped in the recommendations put forward; as such, there is an opportunity to identify and to develop socioeconomic indicators that can be reliably measured and regularly tracked. There is an additional need to develop the indicators in a manner that calls attention to issues of distributional equity (Bullard 1996; Mohai et al. 2009). The engagement of a larger number of social science experts (Weaver et al. 2014) is essential in advancing these goals.

One of the goals of a national indicator system is to assess the effectiveness of adaptation actions to manage the risks of climate impacts (Kenney et al. 2018; Moss et al. 2019; Janetos 2020). Developing adaptation indicators is a combination of first identifying climate impact and vulnerability indicators expected to respond to specific types of adaptation actions and second developing counterfactuals to assess the relative effectiveness of these actions. Because of the diversity of adaptation types (Biagini et al. 2014), additional adaptation accounting and effectiveness indicators will need to be established to evaluate different adaptation strategies.

To support such adaptation and mitigation decisions, the indicator system will need to expand beyond lagging and concurrent indicators to adopt leading indicators that predict and project changes in key decision objectives. Several leading climate indicators have been well-established and communicated, such as radiative forcing, temperature, and precipitation. There is an opportunity to develop multi-stressor leading indicators; for example, the field of ecological forecasting (Dietze et al. 2018) is aimed at iterative, verifiable predictions that integrate climate outlooks and are aimed at supporting decisions.

With the development of any indicator or system of indicators, there is a need to evaluate the effectiveness of such decision support tools for their intended audiences (Moss et al. 2014). Advancements in understanding and testing visual climate communication in the past several years (Gerst et al. in preparation, 2017, 2020; Dasgupta et al. 2015; McMahon et al. 2015; Harold et al. 2016; Wiggins et al. 2019) create an opportunity for the implementation of an iterative design and refinement process that improves indicators as boundary objects (Kenney et al. 2016, 2018).

Finally, the indicator system could be proposed, developed, tested, and revised incrementally (see process and inclusion criteria presented in Kenney et al. (2016)) by leveraging the expertise of the NCA authors to develop an indicator or two to include as part of their chapter during the episodic updates. Indicators included in previous reports can be operationalized through periodic updates as part of or in between the publication of future NCA reports. Over time, we would be able to collectively build a large, robust indicator system of climate changes, impacts, vulnerabilities, and preparedness to assess the status, changes, and trends of key resources and phenomena to advance our understanding and to support decisions.

Acknowledgments Kenney's work was supported by the National Oceanic and Atmospheric Administration grants NA09NES4400006 and NA14NES4320003 (Cooperative Climate and Satellites-CICS) at the University of Maryland/ESSIC. Janetos was supported by Boston University. The National Environmental Modeling and Analysis Center at the University of North Carolina-Asheville and specifically Caroline Dougherty, Karin Rogers, Ian Johnson, and Jim Fox collaborated on the prototype indicators visual style for the pilot. Current and previous Indicators Research Team members, who supported this work or indicator expert teams, include Michael D. Gerst, Ainsley Lloyd, Allison Baer, Rebecca Aicher, Felix Wolfinger, Omar Malik, Sarah Anderson, 
Julian Reyes, Samantha Ammons, Amanda Lamoureux, Maria Sharova, Eric Golman, Ella Clarke, Ryan Clark, Christian McGillen, Justin Shaifer, Olivia Poon, Jeremy Ardanuy, Ying Deng, Marques Gilliam, Andres Moreno, Jordan McCammon, Naseera Bland, and Michael Penansky. Members of the Indicators Technical Teams and NCADAC Indicators Working Group are included in Kenney et al. (2014).

Authors' contributions Melissa Kenney wrote this article. It synthesizes our work over the past 10 years, the articles included in this special issue, and does not contain original analyses.

Funding Kenney's work was supported by the National Oceanic and Atmospheric Administration grant NA09NES4400006 and NA14NES4320003 (Cooperative Climate and Satellites-CICS) at the University of Maryland/ESSIC. Janetos was supported by Boston University.

Data availability Not applicable.

\section{Compliance with ethical standards}

Conflicts of interest The authors declare that there is no conflict of interest.

Code availability Not applicable.

Open Access This article is licensed under a Creative Commons Attribution 4.0 International License, which permits use, sharing, adaptation, distribution and reproduction in any medium or format, as long as you give appropriate credit to the original author(s) and the source, provide a link to the Creative Commons licence, and indicate if changes were made. The images or other third party material in this article are included in the article's Creative Commons licence, unless indicated otherwise in a credit line to the material. If material is not included in the article's Creative Commons licence and your intended use is not permitted by statutory regulation or exceeds the permitted use, you will need to obtain permission directly from the copyright holder. To view a copy of this licence, visit http://creativecommons.org/licenses/by/4.0/.

\section{References}

Anderson SM, Heath LS, Emery MR, et al (in preparation) Developing a set of indicators to identify, monitor, and track impacts and change in forests of the United States. Clim Change

Biagini B, Bierbaum R, Stults M et al (2014) A typology of adaptation actions: a global look at climate adaptation actions financed through the global environment facility. Glob Environ Chang 25:97-108. https://doi.org/10.1016/j.gloenvcha.2014.01.003

Bruhwiler L, Basu S, Butler J, et al (in preparation) Observations of greenhouse gases as climate indicators. Clim Change

Buizer JL, Fleming P, Hays SL, et al (2013) Report on preparing the nation for change: building a sustained national climate assessment process. Washington, D.C

Buizer JL, Dow K, Black ME et al (2016) Building a sustained climate assessment process. Clim Chang 135:2337. https://doi.org/10.1007/s10584-015-1501-4

Bullard RD (1996) Unequal protection: environmental justice and communities of color. Sierra Club Books, San Francisco

Clay PM, Howard J, Busch DS, et al (in preparation) Ocean and coastal indicators: understanding and coping with climate change at the land-sea interface. Clim Change

Dasgupta A, Poco J, Wei Y et al (2015) Bridging theory with practice: an exploratory study of visualization use and design for climate model comparison. IEEE Trans Vis Comput Graph 21:996-1014

Dietze MC, Fox A, Beck-Johnson LM et al (2018) Iterative near-term ecological forecasting: needs, opportunities, and challenges. Proc Natl Acad Sci 115:1424-1432. https://doi.org/10.1073/pnas.1710231115 
Gerst MD, Kenney MA, Wolfinger JF, et al (2017) Effective visual communication of climate indicators and scientific information: synthesis, design considerations, and examples. Tech Input Rep 4th Natl Clim Assess Rep Version 2.0

Gerst MD, Kenney MA, Baer AE et al (2020) Using visualization science to improve expert and public understanding of probabilistic temperature and precipitation outlooks. Weather Clim Soc 12:117-133. https://doi.org/10.1175/WCAS-D-18-0094.1

Gerst MD, Kenney MA, Feygina I (in preparation) Improving the usability of climate indicator visualizations through diagnostic design principles. Clim Change

Harold J, Lorenzoni I, Shipley TF, Coventry KR (2016) Cognitive and psychological science insights to improve climate change data visualization. Nat Clim Chang 6:1080-1089

Hatfield JL, Antle J, Garrett KA et al (2018) Indicators of climate change in agricultural systems. Clim Chang. https://doi.org/10.1007/s10584-018-2222-2

Jacobs KL, Buizer JL, Moser SC (2016) The third US national climate assessment: innovations in science and engagement. Clim Chang 135:1-7. https://doi.org/10.1007/s10584-016-1621-5

Janetos AC (2020) Why is climate adaptation so important? What are the needs for additional research? Clim Chang 161:171-176. https://doi.org/10.1007/s10584-019-02651-y

Janetos AC, Kenney MA (2015) Developing better indicators to track climate impacts. Front Ecol Environ 13: 403-403. https://doi.org/10.1890/1540-9295-13.8.403

Janetos AC, Chen RS, Arndt D et al (2012) National climate assessment indicators: background, development, \& examples. Pacific Northwest National Laboratory, Richland

Jones MO, Running SW, Kimball JS et al (2018) Terrestrial primary productivity indicators for inclusion in the National Climate Indicators System. Clim Chang. https://doi.org/10.1007/s10584-018-2155-9

Kenney MA, Gerst MD (in review) Synthesis of indicators, datasets, and frameworks available to establish resilience and adaptation indicators: case study of Chesapeake Bay Region, USA. Curr Clim Change Rep

Kenney MA, Janetos AC, et al (2014) National Climate Indicators System Report. Washington, D.C

Kenney MA, Janetos AC, Lough GC (2016) Building an integrated U.S. national climate indicators system. Clim Chang 135:85-96. https://doi.org/10.1007/s10584-016-1609-1

Kenney MA, Janetos AC, Gerst MD (2018) A framework for national climate indicators. Clim Chang. https://doi.org/10.1007/s10584-018-2307-y

Liu AY, Trtanj JM, Lipp EK, Balbus JM (in preparation) Toward an integrated system of climate change and human health indicators: a conceptual framework. Clim Chang

Lorente M, Gauthier S, Bernier P, Ste-Marie C (2018) Tracking forest changes: Canadian Forest Service indicators of climate change. Clim Chang. https://oi.org/10.1007/s10584-018-2154-X

McMahon R, Stauffacher M, Knutti R (2015) The unseen uncertainties in climate change: reviewing comprehension of an IPCC scenario graph. Clim Chang 133:141-154

Mohai P, Pellow D, Roberts JT (2009) Environmental Justice. Annu Rev Environ Resour 34:405-430. https://doi.org/10.1146/annurev-environ-082508-094348

Moss R, Scarlett PL, Kenney MA et al (2014) Decision support: connecting science, risk perception, and decisions. In: Melillo JM, Richmond TTC, Yohe GW (eds) Climate Change Impacts in the United States: The Third National Climate Assessment. U.S. Global Change Research Program, pp 620-647

Moss RH, Avery S, Baja K et al (2019) Evaluating knowledge to support climate action: a framework for sustained assessment. Report of an independent advisory committee on applied climate assessment. Weather Clim Soc 11:465-487. https://doi.org/10.1175/WCAS-D-18-0134.1

Ojima DS, Aicher R, Archer SR, et al (2020) A climate change indicator framework for rangelands and pastures of the United States. Clim Change (in review)

Peters-Lidard CD, Rose KC, Kiang J, et al (in preparation) Indicators of climate change impacts on the water cycle and water management. Clim Change

Rose $\mathrm{KC}$, Bierwagen $\mathrm{B}$, Bridgham SD, et al (in preparation) Indicators of the effects of climate change on freshwater ecosystems. Clim Change

Solecki WD, Rosenzweig C (2020) Indicators and Monitoring Systems for Urban Climate Resiliency. Clim Change (in review)

Stanitski DM, Intrieri JM, Druckenmiller ML, et al (in preparation) Indicators for a Changing Arctic. Clim Change

U.S. Global Change Research Program (2010) Ecosystem responses to climate change: selecting indicators and integrating observational networks. Washington, D.C

U.S. Global Change Research Program (2011a) Monitoring climate change and its impacts: physical climate indicators. Washington, D.C

U.S. Global Change Research Program (2011b) Societal indicators for the national climate assessment

U.S. Global Change Research Program (2018) Impacts, risks, and adaptation in the United States: the Fourth National Climate Assessment, vol II. U.S. Global Change Research Program, Washington 
Weaver CP, Mooney S, Allen D et al (2014) From global change science to action with social sciences. Nat Clim Chang 4:656-659. https://doi.org/10.1038/nclimate2319

Weltzin JF, Betancourt JL, Cook BI et al (2020) Seasonality of biological and physical systems as indicators of climatic variation and change. Clim Chang. https://doi.org/10.1007/s10584-020-02894-0

Wiggins A, Young A, Kenney MA (2019) Exploring visual representations to support data re-use for interdisciplinary science. Proc Assoc Inf Sci Technol 55:554-563. https://doi.org/10.1002/pra2.2018.14505501060

Wilbanks TJ, Zimmerman R, Julius S, et al (2020) Toward indicators of the performance of U.S. infrastructures under climate change risks. Clim Change (in review)

Additional Information This article is part of a Special Issue on "National Indicators of Climate Changes, Impacts, and Vulnerability" edited by Melissa A. Kenney and Anthony C. Janetos.

Tony Janetos died peacefully on August 6, 2019, from pancreatic cancer. Those of us who worked with Tony on indicators are still feeling grief over the loss of a colleague and friend. Tony's legacy is chronicled in a remembrance authored by many of his colleagues and friends.

https://blogs.scientificamerican.com/observations/remembering-anthony-janetos/

Tony's work over the past several decades synthesizing the impacts of climate change, analyzing mitigation and adaptation solutions, and communicating this work to diverse audiences is one of his greatest achievements. Our work on indicators is the culmination. When Tony and I started envisioning a system of national climate indicators a decade ago, Tony pulled out all the stops to get an innovative and pragmatic team of experts to work on this challenge with us. And together we were able to make influential recommendations and prototypes that created one of the first sustained assessment products of the US National Climate Assessment. This special issue is Tony's and our collective longer-term vision and legacy for what ought to be developed, both processes and products, as indicators in support of the US National Climate Assessment.

Publisher's note Springer Nature remains neutral with regard to jurisdictional claims in published maps and institutional affiliations. 